\title{
A Curriculum Model for Multidisciplinary Training of Midwife Sonographers in a Low Resource Setting
}

\author{
Sudhir Vinayak (D) \\ Marleen Temmerman (D) 2,3 \\ Geert Villeirs (D) ${ }^{4}$ \\ Sharon M Brownie (iD ${ }^{5-7}$ \\ 'Department of Medical Imaging, Aga Khan \\ University Hospital, Nairobi, Kenya; \\ ${ }^{2}$ Department of Obstetrics \& Gynaecology, \\ Aga Khan University Hospital, Nairobi, \\ Kenya; ${ }^{3}$ Department of Obstetrics \& \\ Gynaecology, Ghent University, Ghent, \\ Belgium; ${ }^{4}$ Department of Diagnostics, \\ Ghent University Hospital, Ghent, Belgium; \\ ${ }_{5}^{5}$ School of Nursing, Midwifery and Public \\ Health, University of Canberra, Canberra, \\ ACT, Australia; ${ }^{6}$ School of Medicine, Griffith \\ University, Queensland, Australia; ${ }^{7}$ Centre \\ for Health and Social Practice, Wintec, \\ Hamilton, New Zealand
}

Abstract: In many low-resource settings, less than 5\% of pregnant women can access ultrasound during pregnancy. Thus, gestational age is often difficult to determine, multiple pregnancies are diagnosed late and foetal and pregnancy-related anomalies can go undetected. A pilot solution was designed beyond the traditional approach of increasing numbers of qualified radiologists, gynaecologists and sonographers. An innovative Human Resource for Health $(\mathrm{HRH})$ task sharing, and maternal child health $(\mathrm{MCH})$ workforce training and capacity building initiative was designed, involving development and testing of a curriculum to train midwife sonographers via a teleradiology innovation platform and a partnership between specialist radiologists, sonographers and midwives. The setting was a tertiary-level private university hospital in Nairobi with implementation in three outreach locations. Direct oversight, support and supervision of specialist radiologists and ultrasonographers effectively addressed issues of quality and safety across the 3-week training period and project implementation. Concepts from sociocultural learning theory informed an initial interactive e-learning module for each midwife at their respective site. Midwives were introduced to ultrasound equipment with a series of didactic and interactive lectures delivered by an expert sonographer at the tertiary hospital teaching site. Lectures were supported by hands-on practical experience, role modelling and mentoring over a four-week period. Assessments included both written examination and practical assessment with an exit examination requiring demonstration of competency in both written and practical format. Final confirmation of scanning accuracy was confirmed with post-delivery verification of results. The pilot was highly successful with an image interpretation accuracy of $99.63 \%$ for the midwives. Lessons from this initiative provides guidance in the curriculum development process along with a curriculum outline; pedagogical framework; teaching methods; assessment processes; credentialing; resourcing; and other considerations in scaling up the program. Importantly, the paper details processes for maintaining a high level of quality control and patient safety. Keywords: maternal health services, ultrasonography, midwifery, education, curriculum, rural health, Kenya

\section{Introduction}

Whilst improvements continue to be made, unacceptably high maternal and neonatal morbidity and mortality persist in Kenya. Health workforce deficits remain problematic and access to core services is limited. ${ }^{1}$ It is estimated that less than $5 \%$ of pregnant women have access to an ultrasound during pregnancy. ${ }^{1}$ Thus, gestational age is often difficult to determine, multiple pregnancies are diagnosed late and foetal and pregnancy-related anomalies can go undetected. Access to ultrasound services can aid reduction in maternal and neonatal mortality, ${ }^{2}$ however,
Correspondence: Sharon M Brownie School of Nursing, Midwifery and Public Health, University of Canberra, Canberra, ACT, Australia

Email sharon.brownie@canberra.edu.au 
the traditional approach to train large numbers of radiologists, gynaecologists and sonographers is not viewed as an achievable solution in addressing the large-scale needs across Kenya's urban and widely dispersed rural populations. Thus, innovative solutions are required for the delivery of affordable and accessible point of care ultrasound service (POCUS) with the combined needs of service users (women in rural and remote settings) and enhanced access goals of the health provider being the key drivers for solution seeking and program development. ${ }^{3,4}$ It is essential; however, innovations and solutions are well constructed and implemented in partnership with an appropriate interprofessional team to avoid sub-optimal results. $^{5}$

Task-sharing is increasingly espoused as a solution to contemporary challenges in human resources for health (HRH) and health service access ${ }^{6}$ with the government of Kenya providing "Task Sharing Policy Guidelines" to guide developments. ${ }^{7}$ An innovative human resource for health (HRH) task sharing and maternal and child health (MCH) workforce capacity building initiative was needed and subsequently developed by an interprofessional team at Aga Khan University Hospital in Nairobi (AKUHN) to enhance access to POCUS services in remote underserved regions. The multi-strategy initiative included the formation and trial of an innovation to train midwife sonographers under the direct oversight, support and supervision of specialist radiologists and sonographers. ${ }^{3,8}$ The task-sharing intervention was designed to deliver a high-quality POCUS with measurable changes in HRH capacity building and proven accuracy in the detection of a range of pregnancy-related anomalies. This paper reports on a curriculum that was developed and implemented and includes evidence of the effectiveness of the program. The innovation involves delivery of POCUS services by an alternate cadre of health workers, specifically, midwives working under the supervision of a specialist radiology team.

\section{Program Development}

Long-standing knowledge exists that workplace education programs need to be developed and contextualized in consideration of what needs to be learnt, who needs to learn it and for what specific reasons. ${ }^{9-11}$ In the absence of any known existing curriculum of relevance to task sharing in rural, low resource contexts, we had to develop a comprehensive program in which three activities were identified as fundamental; 1) establishment of a collaborative inter-professional partnership between the
AKUHN Radiology department and rurally located midwives; 2) identification of an appropriate pedagogical framework to guide development of a pilot curriculum; and 3) obtaining ethics approval to support shared learning via publication and dissemination of the program outcomes and lessons learned. The pilot programme adopted a case study with included features of design, measurement, evaluation and reporting.

\section{Selection of Partners}

Pregnancy-related ultrasound techniques needed to be taught to an appropriate cadre of health providers, namely midwives, working in vastly dispersed rural and remote locations. Midwives were chosen as the ultimate partners of choice on the basis that well-trained midwives are readily available in large numbers; they are close to mothers and babies and, because they have existing knowledge of anatomy and obstetric care. The midwives who participated in this program pilot had no previous experience of ultrasound but were passionate about learning this new skill and expanding services for mothers in remote settings.

\section{Pedagogical Framework}

Prior to designing the program, we engaged discussion about how to identify a pedagogical framework of a guiding theory, educational concepts, teaching methods and instructional techniques that would most effectively support midwife learning in a work-based context. Fundamental to the question was "what do we need to teach?" and "how do we best help our partnering midwives to learn this?" The question required consideration of the most relevant educational concepts and theories to underpin curriculum design and delivery, which included the sociocultural learning theory, experiential learning, constructivism and role modelling. ${ }^{12,13}$ These were translated into a practical training curriculum including collaborative activities (dynamic interaction between teachers and trainees), hands-on activities (practicing skills of performing ultrasound and transmitting images for specialist review), building on prior knowledge (engagement of midwives having an existing knowledge of female anatomy) and allocation of a personal mentor from the radiology department.

\section{Ethics Approval}

In undertaking the study, we were clear in the view that the pilot program and its outcomes must be fully documented, evaluated, reported and published to ensure accountability 
for resources invested and provide opportunity for shared learning. Publication of methods, lessons and outcomes was also deemed to be important for potential replication and scale-up of the initiative. Thus, ethical approval was sought for program development, evaluation and dissemination of results prior to the commencement of the program. Approval was granted by the AKU Ethics and Research Committee (ERC), Nairobi Ref: 2014/REC58 (v2).

\section{The Underlying Learning Theory}

Sociocultural theory posits the notion that learning includes a "social" component with learning viewed as a social process requiring interaction with others. ${ }^{12-14}$ First developed by Vygotsky (1978), the theory recognizes the culture and context in which learning takes place and the power of relationships that influences learning or otherwise. ${ }^{15}$ In short, learning occurs when participation extends beyond written format alone. Learning is facilitated when linguistic exchange occurs in a social context relevant to what is taught and to be learned. ${ }^{10,13,16}$ The theory also promotes the notion that an optimal learning context includes the psychological tools necessary to support learning, particularly linguistic tools. Overall, learning occurs within a "zone of proximal development" in which learning is matched with the individual development level of the student in an appropriate context of social and cultural exchange. ${ }^{15,17}$

Thus, application of the sociocultural model of learning requires construction of authentic collaborative activities a dynamic interdependence between the learning, teacher, culture and environment. ${ }^{14}$ It also involves scaffolding learning to build on existing knowledge, engaging the learner in social learning teams, and, ensuring on-line learning and technological innovations include interactive exchange. ${ }^{17,18}$

\section{Aligned Educational Concepts}

Educational concepts such as "experiential learning" and "constructivism" align closely with sociocultural learning theory. The first notions of "experiential" learning can be traced to early 20th Century the work of John Dewey, an American educational philosopher renowned for his promotion of "learning by doing" rather than passive absorption of oral or written content. ${ }^{19}$ Dewey's concept of active interaction in practice environments continues to inform contemporary pedagogical frameworks and is used widely in transformative health professional education. ${ }^{20,21}$ The implication for this project was to ensure that the curriculum included a strong component of hands on skills; performing an ultrasound and transmitting images for specialist review.

Constructivism is a concept about how people learn. The concept asserts the notion that people learn best by active engagement in the learning process and if the educator first acknowledges what the learner already knows., ${ }^{9,22}$ Constructivism acknowledges and values the learner, actively engages them in the process of learning by continuous exchange about what they know and what they need to learn next. The roots of this idea originate from American Psychologist David Ausubel who developed the idea of "advance organizers" which link what students already know with what they are about to learn. ${ }^{22,23}$ "The most important single factor influencing learning is what the learner already knows. Ascertain this and teach him [or her] accordingly" (Ausubel, 1968 p. vi). This project drew on midwives existing knowledge of female anatomy and the birth process and taught new knowledge and skills in pregnancy-related point of care ultrasound.

\section{Role Modelling and Mentoring}

Positive role modelling and work-based mentoring have been shown to strengthen the context and culture of learning, support the learning process and enhance overall learning outcomes. ${ }^{24,25}$ Horsburgh and Ippolito (2018) provide useful insights to the value of positive role models and mentors in clinical contexts. Characteristics valued by students was the presence of a role model and/or mentor who is present and involved, has aligned values, engaged in meaningful reflection, provides time for a student to write things down, give abundant opportunity for practice, and provides feedback. ${ }^{16}$ Specialist radiologist provided strong role modelling in the program and each midwife was allocated a personal mentor from the radiology department.

\section{The Setting}

The underlying problem that the program developers were seeking to address was that of POCUS access in remote, low resource settings. Thus, the trial initiative sought to test implementation across a wide geographic range. On this basis, a decision was made to develop and pilot a curriculum with midwives working in three different Kenyan locations. A participating midwife was recruited from each setting. Outreach health service centres of the Nairobi-based university teaching hospital were chosen as the pilot sites, namely, Kiambu, Embu and Malindi (see Figure 1). 


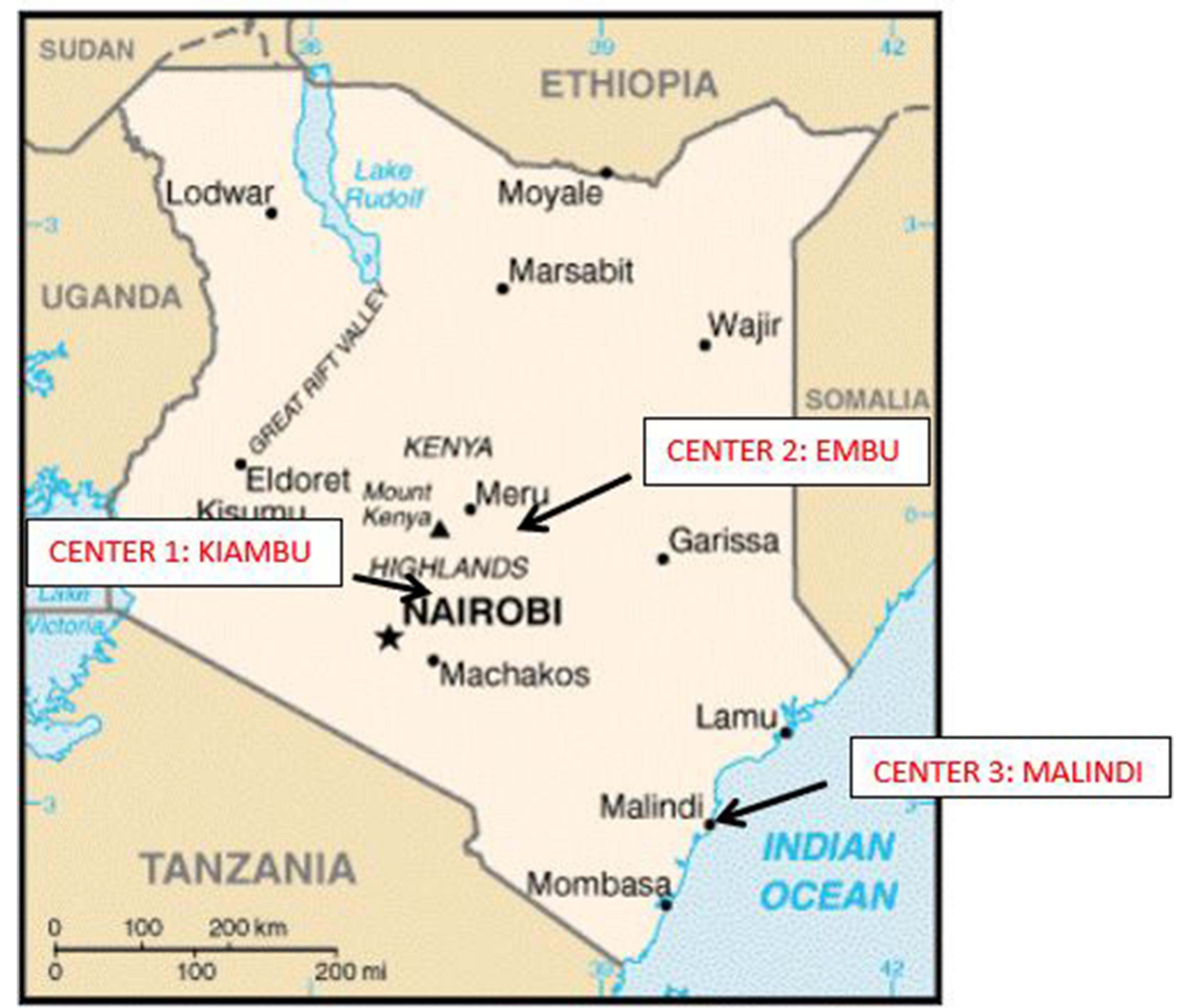

Figure I Location of Centres.

The chosen locations were situated 20, 120 and 400 kilometers respectively from the base training site to enable post-training testing of midwife competencies along with the functionality of the mobile and teleradiology transmissions over a range of distances. ${ }^{3}$

\section{Assessment of Existing Knowledge}

All the midwives were assessed for their knowledge of anatomy, fetal development and maternal characteristics of pregnancy. Twenty-two interested midwives applied for inclusion in the program. Willingness to participate in the research initiative was an important pre-requisite. The six candidates with the strongest base knowledge were selected. They were then interviewed to ascertain their commitment to study while continuing in full-time work. From this group, three were selected for the program; all had less than 3 years' experience in midwifery and they volunteered to undertake the required level of education, which showed their willingness and interest in learning new skills. None of them had any previous experience in performing ultrasound or interpreting ultrasound images.

\section{Curriculum Overview}

The implemented curriculum included a e-learning module on entry, followed by a week of basic training, three weeks of advanced training with increasing levels of competency requirements, and two days of pre-exit testing. Figure 2 provides an overview of the developed curriculum.

\section{E-Learning Module}

The curriculum was designed to begin with an interactive e-learning module developed to provide instruction to the midwives at their "offsite" locations. Initial instruction focused on properties of ultrasound Physics offered within two consecutive courses:

- Theory of Ultrasound Physics - an introduction to sound, sound waves and how medical ultrasound works. The theory describes the different techniques and safety of ultrasound waves; including biologic effects of ultrasound and the interaction of ultrasound with tissue.

- Practical Physics for optimal Image Quality in Ultrasound 


\begin{tabular}{|c|c|}
\hline ENTRY & $\begin{array}{l}\text { E-LEARNING MODULE } \\
\text { Basic knowledge: Introduction to general principles of ultrasound, physics and } \\
\text { ultrasound specific to obstetrics } \\
\text { Required pass mark } 100 \%\end{array}$ \\
\hline Week 1 & $\begin{array}{l}\text { BASIC TRAINING } \\
\text { a. Introduction to ultrasound equipment, knobology and series of didactic lectures } \\
\text { b. Hands-on scanning of phantoms } \\
\text { c. Observing scans performed by experienced sonographers }\end{array}$ \\
\hline Week 2 & $\begin{array}{l}\text { ADVANCED TRAINING I } \\
\text { a. General and obstetric ultrasound } \\
\text { b. Lectures followed by hands-on practical experience under direct observation } \\
\text { c. Progression of independent scanning under observation }\end{array}$ \\
\hline Week 3 & $\begin{array}{l}\text { ADVANCED TRAINING II } \\
\text { a. Feedback and matters arising were addressed in the lecture room } \\
\text { b. Practical work continued to progress. } \\
\text { c. Connected care training for tele-radiology }\end{array}$ \\
\hline Week 4 & $\begin{array}{l}\text { ADVANCED TRAINING III } \\
\text { a. Direct observation of practice skills (DOPS) } \\
\text { b. Final examination designed to test both written and practical skills } \\
\text { Required Pass Mark } 90 \%\end{array}$ \\
\hline $\begin{array}{l}\text { EXIT } \\
\text { Week } 5 \\
2 \text { days }\end{array}$ & $\begin{array}{l}\text { EXIT PROCEDURES } \\
\text { a. Complete set up of remote desk top and scan facility } \\
\text { b. Dummy run from remote set up } \\
\text { c. Connectivity application using cellphone modem }\end{array}$ \\
\hline
\end{tabular}

Figure 2 Curriculum Overview. 
After completing the e-learning modules, trainees sat a structured test. Pass mark was competency-based with a $100 \%$ competence requirement. If $100 \%$ competence was not achieved in the first instance, reexamination was available until the required level of performance was achieved.

\section{Basic Training}

Midwives then progressed to basic training which included introduction to ultrasound equipment including knobology (which involves adjusting keyboard knobs to get optimal diagnostic quality images). Teaching included didactic lectures and hands-on practice in keeping with the pedagogical framework. Midwives learnt about:

- The different modes of ultrasound imaging

- Practical machine operating skills

- Recognizing how adjusting depth, focus, Time Gain Compensation (TGC) can improve ultrasound images.

- Identification and troubleshooting of common imaging artifacts.

This was followed by scanning of phantoms and thereafter, direct observation of experienced sonographers performing obstetric scans in the department.

\section{Advanced Training, I}

The trainee midwives started performing obstetric ultrasound under direct observation. Didactic lectures continued to keep pace with their learning experience. During this period, there was one-on-one supervision of scanning of women had had consented to being scanned by a midwife in training. The trainees became more independent but were never left to scan on their own.

Trainee midwives learnt why and how to perform OB Ultrasound exams in the second and third trimesters of pregnancy, how to evaluate and recognize normal maternal and fetal anatomy and how to evaluate multiple pregnancies.

\section{Advanced Training, II}

Trainees continued to gain confidence as an outcome of increased practice. They were mentored to the point of being able to independently scan patients with limited help and assistance. They could confidently measure fetal biometrics, estimate fetal age, calculate estimated fetal weight (EFW), determine placental position, fetal lie and measure amniotic fluid index (AFI). An introduction to "connected care" hardware for tele radiology was then provided to complete this aspect of the training.

\section{Advanced Training, LII}

After gaining enough experience during the final week, the competency of the trainee Midwives was assessed using the following practical and summative assessments:

- Direct observation of procedural skills (DOPS)

DOPS is an evidence-based assessment used to guide trainee learning and competency. The DOPS form is filled while the trainee scans a patient and a minimum of ten competencies were assessed by grading them on a scale of 1-10 as unsatisfactory/satisfactory and above expected.

The assessor then wrote a short summary and a final mark awarded for their practical skills. The pass mark was 9/10.

- Final examination to test knowledge (90\% pass mark)

Questions were specifically based on the curriculum of training.

\section{Exit Procedures}

- Remote desk set up: A PC desktop, identical to the remote desk which would be used at the scan sites was set up to simulate the remote clinic site. The nurses practiced on sending and receiving images and reports, receiving them back for correction and final validation.

- Connected care competency test: The IT department assessed each nurse on their ability to use the tele radiology software. All the nurses were able to seamlessly use the system.

- Connectivity and transmission using cellphone and modem: The cell phones to be used for the study were issued to the nurses with a compatible modem. They were quick to learn how to use them. Most remote desk testing was done using the cell phones.

\section{Quality Checkpoints}

A major reservation for professional groups considering a task-sharing exercise is the issue of quality and safety wherein any unresolved concerns can cause major hesitation in the implementation processes. ${ }^{26}$ Thus, quality and the implication for patient safety was a key consideration in the design of the curriculum for this project. The importance of clear curriculum and quality assurance 
(QA) checks is reinforced when considering a similar Nairobi-based initiative. Figure 3 provides a pictorial overview of the quality checkpoints within the program.

\section{QA Check: Entry}

The first quality control check occurred prior to program commencement wherein midwives undertook an MCQ entry to confirm an existing knowledge base deemed necessary for safe practice and successful completion of the program.

\section{QA Check: Basic Training}

Basic training provided midwives with time to learn with the direct guidance of qualified radiologists and sonographers. Initial hands-one practice involved the midwives working with phantoms. This was an important quality and safety feature with first experience scanning women occurring only after the acquisition of the required level of base knowledge and skills.

\section{QA Check: Advanced Training I- III}

Movement through the advanced training modules I-III allowed the trainee midwives space and time to increase competency levels in a context of safety will also reducing time to scan. Emphasis was placed on "doing the right things" rather than speed. Subsequently, improvements in time to scan occurred as competency levels increased. Initial scanning time to validation of reports was typically 35 minutes at the beginning of the study, reducing to 25 minutes as the study progress and 15 minutes on program completion. $^{3}$

\section{QA Check: Exit}

Every step of the pilot program involved aspects of monitoring and testing with each test point designed to ensure program quality and safety. Thus, the final exit point involved a dummy run to test connectivity between the remote locations and the centre. The test ensured that the midwives were able competently utilize the modem connections to remotely transmit the necessary images and measurements back to the centre.

\section{Results}

Following training the quality checks occurred at two key points. The first was the point at which each midwife was back in location and engaged in active ultrasonography practice. Images from each ultrasound were transmitted for evaluation and interpretation by a specialist radiologist at
AKUHN hospital. The second point of evaluation occurred post-delivery whereby the accuracy of ultrasound examination and diagnosis could be checked in the immediate after birth period. Collectively, the midwives completed a total of 271 ultrasound scans. All data including images and associated measurements was analyzed by two fully qualified radiologists within AKUHN who concluded that the images and measurements were consistent with the agreed standards and criteria within the standardized methodology. ${ }^{3}$ The accuracy of the images and measurements of scans undertaken by midwives was $99.63 \%$ as shown in Table 1.

Post-delivery tracing provided an additional quality checkpoint to confirm the quality, safety and effectiveness of the training pilot. Out of the 271 patients, 220 were traced to confirm the final pregnancy outcome of which 20 were assessed as having ultrasound findings requiring further investigation. ${ }^{3}$ Analysis of post-delivery outcomes identified three patients with adverse factors that had not been detected on ultrasound (see Table 2). The first involved a child with Down's syndrome, however, the midwives had not been trained to screen for trisomies as this was not within the scope of the training. The second involved a still birth following severe ante-partum hemorrhage of unknown cause. The supervising radiologist confirmed that the placenta had been fundal. The third involved an intra-uterine death of unknown cause. Again, the scans were re-checked by a specialist radiologist and no cause identified. Albeit these three adverse outcomes, analysis of the ultrasounds of the 20 women with findings outside the normal range, highlighted competent assessments by the midwife sonographers. All women with twins, breech, low-lying placement, and intra-uterine growth restriction of wrong dates was correctly identified (see Table 2). A minor discrepancy was noted in the date attribution for the scan of two women only who were noted to have reduced amniotic fluid, however, progression of their pregnancies and the subsequent delivery was normal. $^{3}$

As a final point of evaluation, all participating women expressed the view that they felt the ultrasound process to be convenient, safe and very reassuring. Of note, all reported increased satisfaction with their antenatal visit experience and that the scanning process fostered stronger bonding between the father and unborn child. ${ }^{3}$ The unexpected reporting of increasing participation of fathers provides important insights for further research. 


\section{QUALITY ASSURANCE (QA) CHECKS}

\section{ENTRY}

\section{E-LEARNING MODULE}

MCQ examination-Pass mark $100 \%$

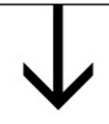

Week 1

\section{BASIC TRAINING}

DOPS - Direct observation of procedural skills by scanning a phantom

Week 2

\section{ADVANCED TRAINING I}

DOPS-Direct observation of procedural skills performing patient obstetric ultrasound examinations

Learning log - generated by the candidate

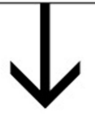

\section{ADVANCED TRAINING II}

DOPS - Direct observation of patient scanning and using the connected care system for tele-radiology

Week 3 Mini-IPX (Mini image interpretation exercise) - Report generated by candidate after a procedure is evaluated based on the image. After evaluation it is altered and a final validated report generated.

Learning log-generated by the candidate; all procedures completed

Week 4

\section{ADVANCED TRAINING III}

DOPS - Examination for practical skills

MCQ-Final examination Pass Mark 90\%

SIRE-Structured image reporting exam

\section{$\sqrt{ }$}

\section{EXIT}

Week 5

\section{EXIT PROCEDURES}

a. Dummy run from remote set up

2 days

b. Passing a connectivity application using cellphone modem

Figure 3 Quality Control Points. 
Table I Accuracy of Image Interpretation of Midwives versus Final Report by Radiologists

\begin{tabular}{|l|c|c|c|}
\hline Women Scanned & Total & Discrepancy & Conformity \\
\hline Number & $27 I$ & 1 & 270 \\
Percentage & 100 & 0.37 & 99.63 \\
\hline
\end{tabular}

Table 2 Outcome of Classified High-Risk Pregnancies (Vinayak et al, 2017)

\begin{tabular}{|l|c|c|}
\hline High-Risk Finding & Number & Outcome Match \\
\hline Breech & 4 & 4 \\
Low placenta? - $2 \mathrm{~cm}$ from os & 1 & 1 \\
Amniotic fluid index $<6 \mathrm{~cm}$ in third trimester & 2 & 0 \\
Twins & 7 & 7 \\
IUGR & 2 & 2 \\
Wrong dates * & 4 & 4 \\
Total & 20 & 18 \\
\hline
\end{tabular}

Note: *Wrong dates defined as discrepancy of more than two weeks also seen on later scans.

\section{Discussion - Insights and Lessons}

A number of important insights arose from this pilot and subsequent analysis. In the first instance the pilot study reinforced the importance of a carefully planned curriculum with a strong assessment and evaluative component. The suitability and relevance of the underlying sociocultural learning theory ${ }^{13,16}$ was reinforced by the inter-professional collegiality that provided a supportive workplace culture and context in which the midwives could learn and increase competence.

We found that the time and practice required to support development to the level of competency required was greater than initially thought. During initial practice each midwife took an average of one hour to complete the scanning process. With focussed role modelling, mentoring and practice each midwife was able to competently complete a scan within a 20-minute time span.

Of importance, the Aga Khan University initiative adhered closely to the Kenya Ministry of Health Task Sharing Guidelines. ${ }^{27}$ The guidelines support workforce flexibility with tasks shared between designated cadres of the health workforce while also protecting public safety. Comparison of outcomes shows the risks associated with the three-day training model ${ }^{28,29}$ versus the outcomes published in association with educational model described herein. ${ }^{3}$ The importance of appropriate prior knowledge such as that held by midwives, sufficient hands-on training, professional supervision and mentorship cannot be overemphasized and was evident in a similar initiative in Rwanda. ${ }^{4}$ The experience also confirmed that monitoring and evaluation are critical in substantiating program quality and the presence of safe outcomes. Those embarking on a similar endeavour should ensure development of a framework for measurement along with the early acquisition of ethics clearance to enable rigorous evaluation and dissemination of outcomes.

Wanjiku, Bell and colleagues (2016-2018) developed and implemented a point-of-care ultrasound training program for rural healthcare providers in Kenya, entitled FAST (Focused Assessment with Sonography for Trauma). The training program was brief involving 81 participants who attended four one-day workshops of which 30 then attended a one-day refresher course. The training provided limited practice opportunity and modelling and mentoring from specialist radiologists and sonographers. An evaluation then included 33 participants across 21 facilities, however, accuracy of results was variable with only nine out of 33 (27.3\%) passing the evaluative observed clinical examination (OSCE). Authors concluded that regular refreshers would be necessary and increased scanning practice would be necessary to enhance POCUS competency among the health professionals involved in the FAST program. ${ }^{28,29}$

Extension of the program from 3 weeks to 4 weeks ensured sufficient time for the acquisition of the competencies needed for the delivery of safe POCUS's by midwife sonographers. Thus, extension of the training is an important consideration for those who may wish to replicate the initiative. Simply put, a competency-based program must be allowed to continue until the point at which the required competencies are present. The experience pointed to the reality that there are no "quick fixes" as evidenced by the cited comparative program (Table 1) which yielded variable results and was not fully evaluated.

The differing outcomes shown in the comparative initiative in Table 3 re-enforces the need for clear quality controls. The longer four-week training involved in this study with post-training follow-up provided a high level of reassurance against the quality and safety indicators and measure. Table 1 provides an overview of the quality outcomes achieved as a result of 2 day versus 4-week training involving extensive supervised practice, specialist role modelling and mentoring. ${ }^{3,28,29}$

Program success is also dependent upon adequate resourcing and a range of logistics such as scheduling 
Table 3 Comparisons Shorter versus Longer Training POCUS Training Programs

\begin{tabular}{|c|c|}
\hline $\begin{array}{l}\text { Four-Week Training Program with Supervision and Extensive } \\
\text { Hands-on Practice }\end{array}$ & $\begin{array}{l}\text { Shorter Training Program with Three One Day Workshops } \\
\text { and One Day Refresher Option }\end{array}$ \\
\hline $\begin{array}{l}\text { Testing Participant Competence: The study involved a robust } \\
\text { measurement and evaluation framework with follow up of patients to } \\
\text { compare in-training ultrasound findings with post-delivery outcome. } \\
\text { The correlation was almost } 100 \% \\
\text { Challenging pass marks were required at the end of the training to } \\
\text { confirm that a robust theory of knowledge had been imparted. The } \\
\text { DOPS assessments over a week confirmed that practical competencies } \\
\text { were at a high level and that the trainees were capable of safe practice }\end{array}$ & $\begin{array}{l}\text { Testing Participant Competence: The study involved three intensive } \\
\text { one day workshops over a two-month period. No matter how intensive } \\
\text { the short training is, the study showed that trainees do not develop } \\
\text { confidence to work independently. Authors noted that periods between } \\
\text { trainings could result in misdiagnosis. The training approach asserted } \\
\text { that while performance of knowledge, skills and theory of knowledge } \\
\text { can be tested in the classroom the real test has to be in the field. The } \\
\text { study did not include comparison of in-training assessment with post- } \\
\text { delivery outcomes. }\end{array}$ \\
\hline $\begin{array}{l}\text { Evaluation: Evaluation showed this to be a robust training program that } \\
\text { gave the trainee midwives confidence to work independently having } \\
\text { completed education in direct partnership with radiologists and } \\
\text { sonographers at main center. }\end{array}$ & $\begin{array}{l}\text { Evaluation: While the training workshops showed promise in promoting } \\
\text { knowledge and practical skills among participants and increases in } \\
\text { patient care, results suggested that refresher training is needed to } \\
\text { provide additional benefits for some participants. }\end{array}$ \\
\hline $\begin{array}{l}\text { Study conclusion: Findings highlight the importance of each step of the } \\
\text { quality processes and reinforce the need for substantive practice-based } \\
\text { 4-week program }\end{array}$ & $\begin{array}{l}\text { ong rationale for the need to } \\
\text { asuring its clinical impact. }\end{array}$ \\
\hline $\begin{array}{l}\text { References: Vinayak, S., Sande, S., Nisenbaum, H., \& Pállson Nolsøe, } \\
\text { C. (20I7). Training midwives to perform basic Obstetric PoCUS in rural } \\
\text { areas using a tablet platform and mobile phone transmission } \\
\text { technology - A WFUMB COE Project. Ultrasound, } 43(I 0), 2|25-2| 32 . \\
\text { Vinayak, S., \& Brownie, S. (20I8). Collaborative task-sharing to enhance } \\
\text { the Point-Of-Care Ultrasound (POCUS) access among expectant } \\
\text { women in Kenya: The role of midwife sonographers. J Interprof Care, } \\
\text { 32(5), 64I-644. }\end{array}$ & $\begin{array}{l}\text { References: Bell, G., Wachira, B., \& Denning, G. (2016). A pilot training } \\
\text { program for point-of-care ultrasound in Kenya. African Journal of } \\
\text { Emergency Medicine, } 6(3), 132-137 \text {. } \\
\text { Wanjiku, G. W., Bell, G., \& Wachira, B. (2018). Assessing a novel point- } \\
\text { of-care ultrasound training program for rural healthcare providers in } \\
\text { Kenya. BMC Health Serv Res, } 18(1), 607 \text {. }\end{array}$ \\
\hline
\end{tabular}

sonographer and radiologist time for training, resources for midwife travel and accommodation to the center, and, the presence of the required technology, mobile tools and telco connections. The absence of adequate training or clear quality contracts can lead to variable outcomes and suboptimal quality within a health service. ${ }^{5}$

From the outset, successful replication of this model is dependent upon a strong collaboration between the task-sharing partners. In line with the experience of others $^{30,31}$ we noted the essential ingredients of trust, mutual respect, open communication, accountability and carefully monitored project management as fundamental to success. Equally, success was dependent upon commitment to a multi-level collaboration between the lead personnel in the Department of Radiology and School of Nursing and Midwifery but also between the midwives, radiologists and sonographers engaged front-line teaching and service delivery.

\section{Limitations}

Whilst highly successful, this study is on a small scale. Scalability is yet to be tested and will require extensive planning and procurement of resources.

\section{Conclusion}

This paper confirms the development of midwife sonographers as a workable and effective solution in improving services for women currently unable to access ultrasound in pregnancy. Guidance is provided in the curriculum development process; a curriculum outline; pedagogical framework; teaching methods; assessment processes; credentialing; resourcing; and, other considerations in scaling up the program. Importantly, the paper details processes for maintaining a high level of quality control and patient safety reinforcing the need for substantive practice-based 4-week program as the minimum standard for safety practice in task sharing with midwife sonographers providing point of care ultrasound services. 


\section{Ethical Approval}

Ethics approval was granted by the Human Research Ethics Committee (HREC) at Aga Khan University, Nairobi Ref: 2014/REC-58 (v2).

\section{Acknowledgments}

Acknowledgement is given to Philips Medical Systems (PMS) who provided funding to support this project and a range of templates adapted for curricula components such competencybased skills checklists. The authors would also like to acknowledge the support and encouragement from the World Federation for Ultrasound in Medicine and Biology in supporting the design and implementation of this project.

\section{Author Contributions}

All authors made a significant contribution to the work reported, whether that is in the conception, study design, execution, acquisition of data, analysis, and interpretation, or in all these areas; took part in drafting, revising or critically reviewing the article; gave final approval of the version to be published; have agreed on the journal to which the article has been submitted; and agree to be accountable for all aspects of the work.

\section{Funding}

Philips Medical Systems (Bothell, WA, USA) provided all the ultrasound machines, e-module, and trainers for the midwives. They fully funded this project hoping that it will be implemented in resource poor areas.

\section{Disclosure}

Dr Sudhir Vinayak reports grants from Philips Medical Systems, during the conduct of the study. Professor Sharon Brownie reports that this study received a grant from Philips Medical Systems, including ultrasound machines. The authors declare no conflict of interest.

\section{References}

1. Keats EC, Ngugi A, Macharia W, et al. Progress and priorities for reproductive, maternal, newborn, and child health in Kenya: a Countdown to 2015 country case study. Lancet Global Health. 2017;5(8):e782-e95. doi:10.1016/S2214-109X(17)30246-2

2. Dagnan NS, Traor Y, Diaby B, Coulibaly D, Ekra KD, Zenby-Acray P. The use of ultrasound to reduce maternal and neonatal mortality in a primary care facility in Ivory Coast. Santé publique. 2013;25(1):95. doi:10.3917/spub.131.0095

3. Vinayak S, Sande S, Nisenbaum H, Pállson Nolsøe C. Training midwives to perform basic Obstetric PoCUS in rural areas using a tablet platform and mobile phone transmission technology - a WFUMB COE Project. Ultrasound. 2017;43(10):2125-2132.
4. Holmlund S, Ntaganira J, Edvardsson K, et al. Improved maternity care if midwives learn to perform ultrasound: a qualitative study of Rwandan midwives' experiences and views of obstetric ultrasound. Glob Health Action. 2017;10(1):1350451. doi:10.1080/ 16549716.2017.1350451

5. Holmlund S, Lan PT, Edvardsson K, et al. Sub-optimal use of ultrasound examinations may result in underperformance of Vietnamese maternity care - A qualitative study of midwives' experiences and views. Sexual Reprod Healthcare. 2020;24:100508. doi:10.1016/j. srhc. 2020.100508

6. Dawson AJ, Buchan J, Duffield C, Homer CSE, Wijewardena K. Task shifting and sharing in maternal and reproductive health in low-income countries: a narrative synthesis of current evidence. Health Policy Plan. 2014;29(3):396-408. doi:10.1093/heapol/czt026

7. Replublic of Kenya. Task Sharing Policy Guidelines: 2017-2030. Health M, editor. Nairobi, Kenya: Republic of Kenya; 2017:1-127.

8. Vinayak S, Brownie S. Collaborative task-sharing to enhance the point-of-care ultrasound (POCUS) access among expectant women in Kenya: the role of midwife sonographers. $J$ Interprof Care. 2018;32(5):641-644. doi:10.1080/13561820.2018.1470499

9. Badyal DK, Singh T. Learning theories: the basics to learn in medical education. Int J Appl Basic Med Res. 2017;Supp 1:S1-S3. doi:10.4103/ijabmr.IJABMR_385_17

10. Hakim EW, Moffat MP, Becker EP, et al. Application of educational theory and evidence in support of an integrated model of clinical education. J Phy Ther Edu. 2014;28:13-21. doi:10.1097/00001416201400001-00005

11. Belfiore ME. Understanding curriculum development in the workplace: a resource for educators. Workplace Education Centre $\mathrm{ABC}$ Canada ABC Canada Canada WECA; 1996.

12. Englund C, Olofsson AD, Price L. The influence of sociocultural and structural contexts in academic change and development in higher education. Higher Edu. 2018;76:1051+. doi:10.1007/s10734-018-0254-1

13. Kahlke R, Bates J, Nimmon L. When I say ... sociocultural learning theory. Med Edu. 2019;53(2):117-118. doi:10.1111/medu.13626

14. Nagel M. Student learning. In: Churchill R, Ferguson P, Godinho S, Johnson N, A K, editors. Teaching Making a Difference. Milton, QLD: Wiley Publishing; 2012:74-88.

15. Vygotsky LS. Mind in Society: The Development of Higher Psychological Processes. Cambridge, Massachusetts, USA: Harvard University Press; 1978.

16. Horsburgh J, Ippolito K. A skill to be worked at: using social learning theory to explore the process of learning from role models in clinical settings. BMC Med Educ. 2018;18:e13.

17. Polly D, Allman B, Casto A, Norwood J. Sociocultural Perspectives on Learning In. West RE, editor. Foundations of Learning and Instructional Design Technology. 2017:1-209. https://edtechbooks. org/lidtfoundations:edtechbooks.

18. Bates B. Learning Theories Simplified. London: Sage; 2019.

19. Quay J, Coherent A. Theory of Experience. In: Quary J, editor. Education, Experience and Existence: Engaging Dewey, Peirce and Heidegger. Melbourne: Australia Routledge; 2013:48-179.

20. Conn JJ, Lake FR, McColl GJ, Bilszta JLC, Woodward-Kron R. Clinical teaching and learning: from theory and research to application. Med J Aust. 2012;196(8):527. doi:10.5694/mja10.11473

21. World Health Organization. Transforming and Scaling Up Health Professionals' Education and Training: World Health Organization Guidelines. Geneva: Switzerland World Health Organization; 2013.

22. Dennick R. Constructivism: reflections on twenty five years teaching the constructivist approach in medical education. Int $J$ Med Edu. 2016;7:200-205. doi:10.5116/ijme.5763.de11

23. Ausubel D. Educational Psychology: A Cognitive View. New York and London: Holt, Rinehart and Winston; 1968.

24. Mikkonen K, Tomietto M, Cicolini G, Kaucic BM. Development and testing of an evidence-based model of mentoring nursing students in clinical practice. Nurse Educ Today. 2020;85:134. 
25. Lutz G, Pankoke N, Goldblatt H, Hofmann M, Zupanic M. Enhancing medical students' reflectivity in mentoring groups for professional development - A qualitative analysis. BMC Med Educ. 2017; 17:546.

26. Feiring E, Lie AE. Factors perceived to influence implementation of task shifting in highly specialised healthcare: a theory-based qualitative approach. BMC Health Serv Res. 2018;18(1):899. doi:10.1186/ s12913-018-3719-0

27. Principal Secretary. Task Sharing Guidelines 2017-2030. Nairobi, Kenya: Ministry of Health Kenya; 2017:1-127.

28. Wanjiku GW, Bell G, Wachira B. Assessing a novel point-of-care ultrasound training program for rural healthcare providers in Kenya. BMC Health Serv Res. 2018;18(1):607. doi:10.1186/s12913-0183196-5
29. Bell G, Wachira B, Denning G. A pilot training program for point-ofcare ultrasound in Kenya. Af J Emerg Med. 2016;6(3):132-137. doi:10.1016/j.afjem.2016.03.002

30. Towe VL, Leviton L, Chandra A, Sloan JC, Tait M, Orleans T. Crosssector collaborations and partnerships: essential ingredients to help shape health and well-being. Health Aff. 2016;35(11):1964-1969. doi:10.1377/hlthaff.2016.0604

31. Musoke P, John CC, Ayodo G. Successful global health research partnerships: what makes them work? Am J Trop Med Hyg. 2016;94(1):5-7. doi:10.4269/ajtmh.15-0611

\section{Publish your work in this journal}

The Journal of Multidisciplinary Healthcare is an international, peerreviewed open-access journal that aims to represent and publish research in healthcare areas delivered by practitioners of different disciplines. This includes studies and reviews conducted by multidisciplinary teams as well as research which evaluates the results or conduct of such teams or healthcare processes in general. The journal covers a very wide range of areas and welcomes submissions from practitioners at all levels, from all over the world. The manuscript management system is completely online and includes a very quick and fair peer-review system. Visit http://www.dovepress.com/testimonials. php to read real quotes from published authors. 